\title{
Products and bioenergy from the pyrolysis of rice straw via radio frequency plasma and its kinetics
}

\author{
Wen-Kai Tu ${ }^{a}$, Je-Lung Shie ${ }^{b}$, Ching-Yuan Chang ${ }^{a, *}$, Chiung-Fen Chang ${ }^{c}$, \\ Cheng-Fang Lin ${ }^{a}$, Sen-Yeu Yang ${ }^{d}$, Jing T. Kuo ${ }^{d}$, Dai-Gee Shaw ${ }^{e}$, Yii-Der You ${ }^{a}$, Duu-Jong Lee ${ }^{f}$ \\ ${ }^{a}$ Graduate Institute of Environmental Engineering, National Taiwan University, 71, Choushan Road, Taipei 10617, Taiwan \\ ${ }^{\mathrm{b}}$ Department of Environmental Engineering, National I-Lan University, No. 1, Sec. 1, Shen-Lung Road, Ilan 26041, Taiwan \\ ${ }^{\mathrm{c}}$ Department of Environmental Science and Engineering, Tung-Hai University, No. 181, Sec. 3, Taichung Harbor Road, Taichung 40704, Taiwan \\ ${ }^{\mathrm{d}}$ Department of Mechanical Engineering, National Taiwan University, No. 1, Sec. 4, Roosevelt Road, Taipei 10617, Taiwan \\ ${ }^{\mathrm{e}}$ Chung-Hua Institution for Economic Research, No. 75, Changsing Street, Taipei 10672, Taiwan \\ ${ }^{\mathrm{f}}$ Department of Chemical Engineering, National Taiwan University, No. 1, Sec. 4, Roosevelt Road, Taipei 10617, Taiwan
}

\section{A R T I C L E I N F O}

\section{Article history:}

Received 21 June 2008

Received in revised form 25 September 2008

Accepted 26 September 2008

Available online 30 November 2008

\section{Keywords:}

Biomass waste

Radio frequency

Rice straw

Bioenergy

Pyrolysis

\begin{abstract}
A B S T R A C T
The radio frequency plasma pyrolysis technology, which can overcome the disadvantages of common pyrolysis methods such as less gas products while significant tar formation, was used for pyrolyzing the biomass waste of rice straw. The experiments were performed at various plateau temperatures of $740,813,843$ and $880 \mathrm{~K}$ with corresponding loading powers of 357, 482, 574 and $664 \mathrm{~W}$, respectively. The corresponding yields of gas products (excluding nitrogen) from rice straw are 30.7, 56.6, 62.5 and $66.5 \mathrm{wt} . \%$ with respect to the original dried sample and the corresponding specific heating values gained from gas products are about $4548,4284,4469$ and $4438 \mathrm{kcal} \mathrm{kg}^{-1}$, respectively, for the said cases. The corresponding combustible portions remained in the solid residues are about 64.7, 35, 28.2 and 23.5 wt.\% with specific heating values of $4106,4438,4328$ and $4251 \mathrm{kcal} \mathrm{kg}^{-1}$ with respective to solid residues, while that in the original dried sample is $87.2 \mathrm{wt}$.\% with specific heating value of $4042 \mathrm{kcal} \mathrm{kg}^{-1}$. The results indicated that the amount of combustibles converted into gas products increases with increasing plateau temperature. The kinetic model employed to describe the pyrolytic conversion of rice straw at constant temperatures agrees well with the experimental data. The best curve fittings render the frequency factor of $5759.5 \mathrm{~s}^{-1}$, activation energy of $74.29 \mathrm{~kJ} \mathrm{~mol}^{-1}$ and reaction order of 0.5 . Data and information obtained are useful for the future design and operation of pyrolysis of rice straw via radio frequency plasma.
\end{abstract}

(c) 2008 Published by Elsevier Ltd.

\section{Introduction}

The bioenergy from biomass, which is estimated to contribute about $10-14 \%$ of the primary energy supply of the world or about $38 \%$ of that of the developing countries (Bhattacharya et al., 2000; Mckendry, 2002), has a potential to provide a significant portion of the projected renewable energy provisions for the shortage of the oil. In general, the feasible characteristics of the biomass are: (1) high yield, (2) low energy input for plantation, (3) low cost, (4) least contaminants and (5) low nutrient requirements (Mckendry, 2002). Therefore, using the biomass wastes becomes a significant way to produce the bioenergy. Among the available biomass wastes, rice straw is one of the favorable waste sources of bioenergy, because it is the residue from the end use of the biomass prod-

\footnotetext{
* Corresponding author. Tel./fax: +88622363 8994.

E-mail address: cychang3@ntu.edu.tw (C.-Y. Chang).
}

ucts. The reutilization of rice straw not only saves the cost of disposal but also produces valuable bioenergy, achieving the goal of resources recovery and reuse. Taiwan locates in the subtropics and has excellent farming technology, thus producing abundant biomasses. However, this also results in a significant amount of agriculture wastes to be treated, with the rice straw contributing the most. In Taiwan, rice is one of the principal foods and the total annual generation of rice straw is about 1.4 million tons (Tu et al., 2008). The rice straw is difficult for burning in most existing combustion systems. The reasons are: (1) the fouling of deposits, (2) slag formation in furnaces and (3) accelerated corrosion (Bakker and Jenkins, 2003). Therefore, its common treatment is in-site burning for producing manure. However, the open burning is harmful to air quality and environment (Pütün et al., 2004).

Transform of the biomass wastes into bioenergy can be efficiently achieved applying thermochemical methods such as combustion, pyrolysis and gasification (Shie et al., 2001,2002a; Chen et al., 2003b; Wu et al., 2003; Pütün et al., 2004). There are two 
main disadvantages of the pyrolysis and gasification of biomass wastes for producing gases of medium calorific value via the traditional thermolysis technology. These are: (1) the low gas yield, reducing the total energy value of gas and (2) the high content of tar in gas, causing the corroding problem of the gas collection equipment and increasing the need for the further treatment of the gas produced (Caldeira et al., 2002; Bridgwater, 2003; Chen et al., 2003a). The biomass treated via thermolysis yields the tar in the inferior temperatures and can undergo the cracking and re-polymerization in the superior temperatures above $673 \mathrm{~K}$ via secondary reactions (Ferdous et al., 2001; Chen et al., 2003b; Pütün et al., 2004). In order to provide the suitable fuel for spark ignition gas engines, the bio-fuel should be either gaseous or high quality liquid form (Mckendry, 2002). The common methods to overcome the above two disadvantages of the traditional thermolysis of biomass are adding catalysts and steam Shie et al., 2002b,c; Gullu, 2003; Atutxa et al., 2005; Demirbas, 2005; Waldner and Vogel, 2005). Worasuwannarak et al. (2007) applied the thermal gravimetry-mass spectrometry technique to study the pyrolysis behaviors of rice straw, yielding the pyrolysis products from rice straw at $873 \mathrm{~K}$ with compositions of char, $\mathrm{H}_{2} \mathrm{O}, \mathrm{CO}, \mathrm{CO}_{2}$, tar and sum of $\mathrm{H}_{2}$ and $\mathrm{CH}_{4}$ of $31,25,15,15,10$ and $4 \mathrm{wt}$.\%, respectively. Thus, other than $\mathrm{H}_{2} \mathrm{O}$, the $\mathrm{CO}$ and $\mathrm{CO}_{2}$ are the dominant gas products, while $\mathrm{H}_{2}$ and $\mathrm{CH}_{4}$ are minor. Chen et al. (2003b) employed the catalysts to pyrolyze the rice straw, improving the gas yields at $1023 \mathrm{~K}$ with respect to the original un-dried sample containing about 10 wt.\% $\mathrm{H}_{2} \mathrm{O}$ from 36 wt.\% without catalyst to $41,42.2$ and 46 wt.\% with $\mathrm{CaO}, \mathrm{Na}_{2} \mathrm{CO}_{3}$ and $\mathrm{Cr}_{2} \mathrm{O}_{3}$, respectively. However, even with the use of the catalyst of $\mathrm{Cr}_{2} \mathrm{O}_{3}$, the yield of tar is still as high as $10 \mathrm{wt} . \%$ at least. Pütün et al. (2004) reported that the feasible parameters for the pyrolysis of rice straw are with particle diameter of 20-40 mesh, gas flow of $200 \mathrm{~mL} \mathrm{~min}^{-1}$, final temperature of $823 \mathrm{~K}$ and the steam velocity of $2.7 \mathrm{~cm} \mathrm{~s}^{-1}$. Huang et al. (2008) employed the microwave-induced technology to pyrolyze the rice straw and yielded the $\mathrm{H}_{2}$-rich fuel gas of nitrogen-free with $\mathrm{H}_{2}$, $\mathrm{CO}_{2}, \mathrm{CO}$ and $\mathrm{CH}_{4}$ of $55,17,13$ and 10 vol.\%, respectively.

Application of a novel heating method via the radio frequency (RF) plasma is one of the feasible choices for overcoming the disadvantages of thermolysis using traditional heating methods (Tu et al., 2008). The RF plasma heating method, which is a capacitive dielectric heating method, employs the alternating current with high frequency and voltage to build up electro-magnetic field producing plasma to induce the target material resulting in the vigorous colliding, rubbing and thus self-heating. As the material is heated, pyrolysis occurs. The heating method using RF plasma has many advantages such as high heating rate, short heating time to reach setting temperature, low heat loss and low residual tar. Hence, this novel method can overcome the problems encountered in the traditional pyrolysis of biomass (Zhao et al., 2001; Bridgwater, 2003; Chen et al., 2003a; Merida et al., 2004; Yaman, 2004; Shie et al., 2008).

The plasma technologies for the thermolysis of biomass not only give high concentration of syngas, but also result in low concentration of tar in gas phase mostly below $10 \mathrm{mg} \mathrm{Nm}^{-3}$ as noted by Hlina et al. (2006). Low tar content in product obtained from RF plasma thermolysis also can be achieved because high energy species, such as electron, ion, atom and free radical produced from RF plasma can enhance the decomposition of tar (Tang and Huang, 2005a,b; Cheng et al., 2007). Tang and Huang (2005a,b) employed RF plasma pyrolysis with $\mathrm{N}_{2}$ as carrier gas at $0.8 \mathrm{~L} \mathrm{~min}^{-1}$ to treat the biomass of sawdust. The gas yield on average with respect to the original dried sample can reach 66 wt.\% consisting of $\mathrm{H}_{2}, \mathrm{CO}$, $\mathrm{CH}_{4}, \mathrm{CO}_{2}$ and $\mathrm{C}_{2}$ at an input power of $1800 \mathrm{~W}$ and an operating pressure of $5000 \mathrm{~Pa}(=0.05 \mathrm{~atm})$. The corresponding compositions of $\mathrm{H}_{2}, \mathrm{CO}, \mathrm{CH}_{4}, \mathrm{CO}_{2}$ and $\mathrm{C}_{2}$ in the gas including $\mathrm{N}_{2}$ are 3.88-11.06, $5.21-14.82,1.38-2.48,1.51-5.05$ and $1.5-3.92$ vol.\%, respectively.
The total content of $\mathrm{CO}$ and $\mathrm{H}_{2}$ in the gas products is 76 vol.\% on a nitrogen-free basis, which can be used as syngas components.

\section{Experimental section}

The original RF plasma pyrolysis system (Tu et al., 2008) was modified adding the gas mixers, electromagnetic pulses stabilization device and effluent flow meter for the use in this study. The electromagnetic pulses stabilization device can stabilize the potential energy of the reactor when the RF plasma is produced and lead the electromagnetic pulses to the ground wire. The modified RF plasma pyrolysis system denoted as RFPT-N system is shown in Fig. 1. The RF plasma reactor consists of a quartz tube with outer diameter of $50 \mathrm{~mm}$, wall thickness of $2 \mathrm{~mm}$ and length of $500 \mathrm{~mm}$. The electrodes are two pieces of copper arcs with length of $320 \mathrm{~mm}$, which are fixed around the outside of the quartz tube with a gap between two electrodes. The length of the RF plasma producing zone is about $320 \mathrm{~mm}$. The electromagnetic pulses stabilization device stabilizes the potential energies of the upper and bottom stainless steel parts, hence preventing the interference of electromagnetic pulses on the digital monitors. Nitrogen with a purity of $99.99 \%$ was used as the working gas. Its flow rate through the drying tube was controlled via a mass flow controller of model 5850E from Brooks, Hatfield, PA, USA and checked by the effluent flow meter. In all experiments, nitrogen flow rate was kept at $200 \mathrm{~mL} \mathrm{~min}^{-1}$. A pressure control valve is adopted to transfer the RFPT-N system from low-vacuum to atmosphere condition smoothly. A cold trap container with a volume of $3 \mathrm{~L}$ for controlling the outlet gas at a temperature of $298 \pm 5 \mathrm{~K}$ is installed after the RF plasma pyrolysis reactor to collect the liquid products. In order to maintain a suitable degree of vacuum in the RFPT-N system, switch valves and vacuum meters of model CVG191GA from InstruTECH Inc., Bellmore, NY, USA, which are recorded by a vacuum monitor of Terranova model 906A from Duniway Stockroom Corp., Mountain View, CA, USA, are installed. Three digital thermometers of model TFC 305A, type K from Macro Fortunate Co., Taipei County, Taiwan were used to measure the temperatures at the inlet and inside of the RF plasma reactor, and the outlet of the cold trap. A RF plasma power supply of model QINTO3013 from Huettinger, Freiburg, Germany and an auto-matching box of model PFM3000A from Huettinger, Freiburg, Germany provide a maximum power of $2000 \mathrm{~W}$ and RF frequency of $13.56 \mathrm{MHz}$. The temperatures were controlled at various constant values from $740 \pm 5$ to $880 \pm 5 \mathrm{~K}$ with the input powers at various constant values from $357 \pm 2$ to $664 \pm 2 \mathrm{~W}$ at the pressure of $0.9 \pm 0.04$ torr. In this study, the RF plasma pyrolysis reactor was used for pyrolyzing the biomass waste of rice straw. In the batch experiments, the sample of rice straw was put in the crucible. After the completion of an experiment, the solid remained in the crucible was weighted. Three replicates were performed.

The effluent gas was vented to a fume hood for starting up and switched to the sampling port for collection using a sample bag as the experimental conditions of RFPT-N system were stable. When the run was finished, the nitrogen gas was kept flowing till the temperature of system was below $373 \mathrm{~K}$.

The Brunauer-Emmett-Teller (BET) surface areas of samples were measured via the specific surface area analyzer of model ASAP2010 from Micromeritics, Norcross, GA, USA adopting gas adsorption method. Before analyzing, the sample was degassed at $378 \mathrm{~K}$ and $10^{-3} \mathrm{mmHg}$. It followed the nitrogen adsorption at $77 \pm 0.5 \mathrm{~K}$. The elements of $\mathrm{C}, \mathrm{H}$ and $\mathrm{N}$ were analyzed via Heraeus CHN-O-Rapid analyzer from Heraeus Ltd., Hanau, Germany, and S and $\mathrm{Cl}$ via Tacussel Coulomax 78 automatic coulometric titrator from Tacussel, Lyons, France. The actual heating values of samples were measured using the adiabatic bomb calorimeter of model 150 


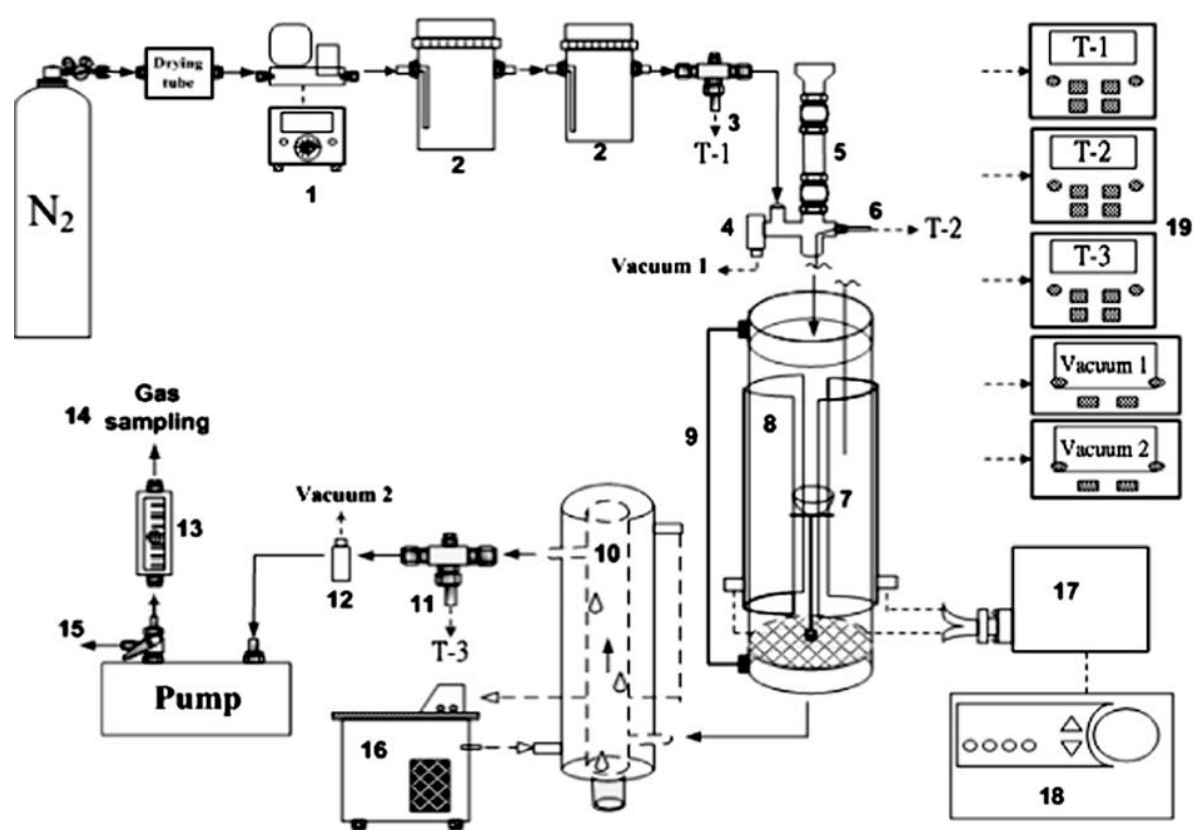

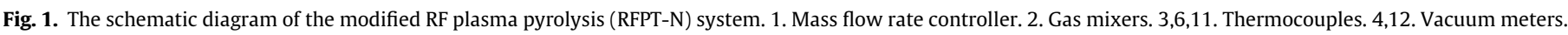

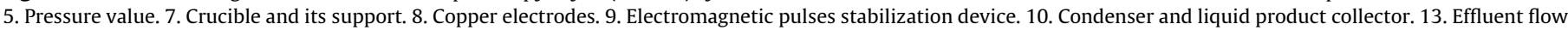
meter. 14. Sampling port. 15. Vent to hood. 16. Circulating thermostat. 17. Auto-matching box. 18. RF plasma power supply. 19. Digital monitors.

Vacuum Flask Oxygen Bomb Calorimeter form Osaka Sanso Kogyo Ltd., Osaka, Japan, while the theoretic heating values of samples were calculated by Scheurer-Kestner formula (Srinivasa Reddy et al., 2005). The actual heating values can be estimated from the change of temperature in the adiabatic bomb calorimeter when the sample was burning and the detailed procedures can be referred to the standard test method for gross calorific value of coal and coke by the adiabatic bomb calorimeter (ASTM D2015, 2000; ASTM D3174-04, 2006).

The gaseous products of $\mathrm{H}_{2}, \mathrm{CO}$ and $\mathrm{CO}_{2}$ were analyzed using gas chromatography-TCD of model 8900 from China Chromatography Co. Ltd., Taipei, Taiwan adopting column of \#1-2390-U with dimensions of $15 \mathrm{ft} \times 1 / 8 \mathrm{inch}$. The temperatures of injector, oven and detector were at 343,368 and $343 \mathrm{~K}$, respectively. The gaseous product of $\mathrm{CH}_{4}$ was analyzed via gas chromatography-FID of model HP 6890 from Hewlett Packard Inc., California, USA using column of \#115432 GS-Q with dimensions of $30 \mathrm{~m} \times 0.530 \mathrm{~mm}$. The temperatures of injector, oven and detector were $373 \mathrm{~K}, 323 \mathrm{~K}$ for $10 \mathrm{~min}$ then raised to $523 \mathrm{~K}$ with heating rate of $10 \mathrm{~K} \mathrm{~min}^{-1}$ and $523 \mathrm{~K}$, respectively. The gaseous products of total hydrocarbons were analyzed using gas chromatography-FID of model HP 5890 from Hewlett Packard Inc., California, USA with column of fused silica capillary tube with dimensions of $10 \mathrm{~m} \times 0.530 \mathrm{~mm}$. The temperatures of injector, oven and detector were 423,423 and $473 \mathrm{~K}$, respectively. The detection limits of $\mathrm{H}_{2}, \mathrm{CO}, \mathrm{CO}_{2}, \mathrm{CH}_{4}$ and THCs are 2.2, 25.9, 21.9, 0.085 and $0.095 \mathrm{mg} \mathrm{L}^{-1}$.

\section{Results and discussion}

\subsection{Effects of loading power on the efficiency of pyrolysis of rice straw via RF plasma}

The rice straw sample was exposed under the sunlight for $10 \mathrm{~d}$, broken via spiral breaker, sieved into 30-40 mesh (0.6-0.425 mm) and dried in a recycle ventilation drier for $24 \mathrm{~h}$ at $378 \mathrm{~K}$ before use. The results of proximate and elemental analyses, heating value and BET surface area of rice straw with respect to the original dried sample are listed in Table 1 . On the dry basis, the heating value is as high as $4042 \mathrm{kcal} \mathrm{kg}^{-1}$ contributed by the high content of the combustibles of rice straw of $87.2 \mathrm{wt} . \%$. The combustibles of rice straw are composed of $84 \pm 5 \mathrm{wt}$.\% of volatile matter and $16 \pm 5$ wt.\% of fixed carbon (Chen et al., 2003b; Iranzo et al., 2004; Pütün et al., 2004; Worasuwannarak et al., 2007; Huang et al., 2008). Thus, the contents of volatile matter and fixed carbon of sample used in this study are 73.2 and $14 \mathrm{wt} . \%$, respectively. The contents of $\mathrm{C}, \mathrm{H}$ and $\mathrm{O}$ of rice straw are 41.8, 5.9 and $51.6 \mathrm{wt} . \%$ on dry basis, respectively, while those of nitrogen, sulfur and chloride are rare and can be neglected in the utilization of rice straw. The BET surface area is small with a value of $1.21 \mathrm{~m}^{2} \mathrm{~g}^{-1}$. The utilization of biomass for producing energy containing products also assists the reduction of $\mathrm{CO}_{2}$ and $\mathrm{SO}_{2}$ emissions for preventing the greenhouse effect and acid rain (Liang and Kozinski, 2000).

Table 1

Some properties of original rice straw $w^{\mathrm{a}}$ used in this study ${ }^{\mathrm{b}}$.

\begin{tabular}{ll}
\hline Item & Value \\
\hline Proximate analysis (wt.\%) & \\
Moisture & 0 \\
Combustibles & $87.2(0.90)^{\mathrm{c}}$ \\
Ash & $12.8(1.15)$ \\
Heating value $\left(\mathrm{kcal} \mathrm{kg}^{-1}\right)$ & 4042 \\
Elemental analyses $\left(\mathrm{wt}_{\mathrm{N}} \%\right)$ & \\
$\mathrm{C}$ & $41.8(0.01)$ \\
$\mathrm{H}$ & $5.9(0.06)$ \\
$\mathrm{N}$ & $0.4(0.01)$ \\
$\mathrm{O}$ & $51.6^{\mathrm{d}}$ \\
$\mathrm{S}$ & $0.2(0.02)$ \\
$\mathrm{Cl}$ & 0.1 \\
$\mathrm{BET}$ surface area $\left(\mathrm{m}^{2} \mathrm{~g}^{-1}\right)$ & 1.212 \\
\hline
\end{tabular}

a Dry basis.

b Note that the samples used in the and present previous studies (Tu et al., 2008) were collected from different farmlands, showing slight difference in properties.

c Numbers in parentheses are standard deviations $\left(\sigma_{n-1}\right)$.

d Balance. 
The residual mass fraction $(M)$ of rice straw with respect to the initial mass during pyrolysis is expressed on a normalized basis as

$M=W / W_{0}$

where $W$ and $W_{0}$ are the present and initial masses of sample, respectively.

The pyrolytic reaction of rice straw is significant in $550-650 \mathrm{~K}$ with two major reaction steps (Tu et al., 2008). Therefore, the plateau temperature for the pyrolysis of rice straw pyrolysis using RF plasma conducted in this study was set at the middle range of the second reaction step $(740 \pm 5-880 \pm 5 \mathrm{~K})$ to ensure an acceptable reaction rate of rice straw.

The effects of major system parameters on the performance of RF plasma pyrolysis of rice straw were examined. These parameters include loading power, reaction time and reaction temperature. The loading power can be measured online and recorded via the RF plasma power supply device. Maintaining the stable value of net pressure in the reactor can ensure the gas flowing through the plasma pyrolysis system with no leakage problem in experiments (Tu et al., 2008). The net pressure is the difference between the final pressure and the initial pressure under vacuum of 89 mtorr. For the followed pyrolysis experiments using RF plasma, the gas flow rate and net pressure of $N_{2}$ were set at $200 \mathrm{~mL} \mathrm{~min}^{-1}$ and $0.90 \pm 0.04$ torr, respectively.

Time variations of residual mass fraction and reaction temperature at various loading powers and plateau temperatures are shown in Fig. 2. The loading power used for the generation of $\mathrm{RF}$ plasma is equal to the input power minus reflected power. The input and reflected powers stand for the power supplied from the RF plasma power supply and the useless power producing the wasted electromagnetic wave from reflection, respectively. The results indicated that as the loading power increases from 357 to $664 \mathrm{~W}$, the final value of residual mass fraction denoted as $M_{\mathrm{f}}$ at $45 \mathrm{~min}$ decreases from 69.3 to $33.5 \mathrm{wt}$ \%, while the plateau temperature of plasma increases from 740 to $880 \mathrm{~K}$. The rate of variation of residual mass fraction decreases while that of reaction temperature increases with the increase of loading power. The corresponding plateau temperatures at various loading powers are $740 \mathrm{~K}$ at $357 \mathrm{~W}, 813 \mathrm{~K}$ at $482 \mathrm{~W}, 843 \mathrm{~K}$ at $574 \mathrm{~W}$ and $880 \mathrm{~K}$ at $664 \mathrm{~W}$, respectively. At loading powers of $357,482,574$ and $664 \mathrm{~W}$, the values of heating times $t_{\mathrm{ST}}$ to reach their corresponding setting temperatures $T_{\mathrm{ST}}$, which are estimated as initial temperature $T_{0}$ plus $95 \%$ of the change of $T_{0}$ to the corresponding plateau temperatures, at $718,787,816$ and $851 \mathrm{~K}$ are about $4.5,4.17,4$ and 3.83 min with heating rates of $98,124,136$ and $152 \mathrm{~K} \mathrm{~min}^{-1}$, respectively. Thus, a higher loading power gives a higher plateau temperature with a shorter $t_{\mathrm{ST}}$, resulting in a high heating rate which can be express as the following equations:

$T_{P}(K)=0.4488 P_{\mathrm{WL}}+585.97 \quad R^{2}=0.984$

$\operatorname{HR}\left(K \mathrm{~min}^{-1}\right)=0.1722 P_{\mathrm{WL}}+38.064 \quad R^{2}=0.9942$

where $T_{\mathrm{P}}, P_{\mathrm{WL}}$ and HR are the plateau temperature, loading power and heating rate, respectively. The values of $T_{\mathrm{P}}$ and HR increase linearly with $P_{\mathrm{WL}}$. Hence, $\mathrm{HR}$ can reach as high as about $152 \mathrm{~K} \mathrm{~min}^{-1}$ at $P_{\mathrm{WL}}$ of $664 \mathrm{~W}$.

The average reaction rate $r_{\text {avg }}$ before steady state can be estimated by further examination of the results of Fig. 2a. At various values of loading power, the values of residual mass fraction and time at steady state symboled as $M_{\mathrm{SS}}$ and $t_{\mathrm{SS}}$ are about $69 \pm 1 \mathrm{wt} . \%$ and $40 \mathrm{~min}$ at $357 \mathrm{~W}, 44 \pm 1 \mathrm{wt} . \%$ and $30 \mathrm{~min}$ at $482 \mathrm{~W}, 37 \pm 1 \mathrm{wt} . \%$ and $20 \mathrm{~min}$ at $574 \mathrm{~W}$, and $33 \pm 1 \mathrm{wt} . \%$ and $15 \mathrm{~min}$ at $664 \mathrm{~W}$. The values of $M_{\mathrm{SS}}$ at $t_{\mathrm{SS}}$ are about equal to their corresponding final values of residual mass fraction $M_{\mathrm{f}}$ at $45 \mathrm{~min}$,
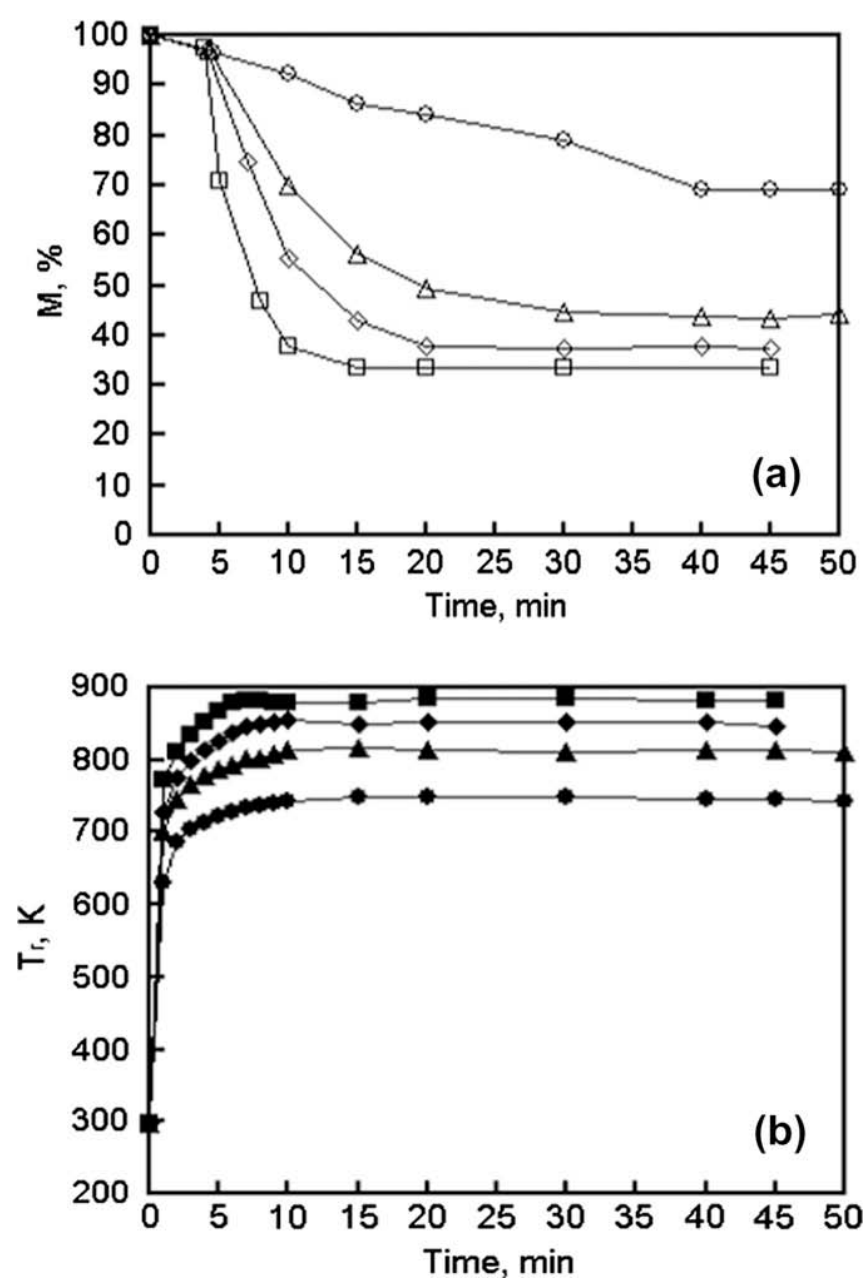

Fig. 2. Time variations of residual mass fraction $(M)$ and reaction temperature $\left(T_{\mathrm{r}}\right)$ for the pyrolysis of rice straw via RF plasma method at various loading powers $\left(P_{\mathrm{WL}}\right)$ of $357 \pm 2(\bigcirc), 482 \pm 2(\triangle), 574 \pm 2(\diamond)$ and $664 \pm 2(\square)$ W with plateau temperature $\left(\mathrm{T}_{\mathrm{P}}\right)$ of $740 \pm 5(\bullet), 813 \pm 5(\Delta), 843 \pm 5(\bullet)$ and $880 \pm 5(\boldsymbol{\square}) \mathrm{K}$, respectively. $P_{\mathrm{WL}}=P_{\mathrm{WI}}$ $-P_{\mathrm{WR}} \cdot P_{\mathrm{WI}}, P_{\mathrm{WR}}$ : Powers supplied and reflected. $W_{0}: 300 \pm 10 \mathrm{mg}$. $\mathrm{d}_{\mathrm{P}}: 0.425-0.6 \mathrm{~mm}$.

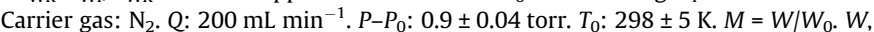
$W_{0}$ : Present and initial masses of sample. $\mathrm{d}_{\mathrm{p}}$ : Sample size. $Q$ : Flow rate of inlet carrier gas. P: Final pressure. $P_{0}$ : Initial pressure $\left(89 \mathrm{~m}\right.$ torr). $T_{0}$ : Initial or room temperature. (a) $M$ vs. time, (b) $T_{\mathrm{r}}$ vs. time.

which are about 69.3, 43.4, 37.5 and 33.5 wt.\%, respectively. As reaction temperature increases from $T_{0}$ to the setting temperature, the residual mass fraction only slightly reduces about 3.5, 2.9, 2.8 and 2.6 wt.\% while retains $96.5,97.1,97.2$ and $97.4 \mathrm{wt} . \%$ denoted as $M_{\mathrm{ST}}$ for the cases with loading power of 357, 482, 574 and $664 \mathrm{~W}$, respectively, for further pyrolysis at various plateau temperatures. The corresponding decomposition efficiency of rice straw for further pyrolysis of $M_{\mathrm{ST}}$ to $M_{\mathrm{SS}}$ symboled as $\eta_{\mathrm{ST} / \mathrm{SS}}$ is given as:

$\eta_{\mathrm{ST} / \mathrm{SS}}=M_{\mathrm{ST}}-M_{\mathrm{SS}}$

The values of $\eta_{\mathrm{ST} / \mathrm{SS}}$ are about $27.5,53.1,60.2$ and $64.4 \mathrm{wt} . \%$, respectively. The values of $r_{\text {avg }}$ of RFPT-N system are estimated to be about $0.78,2.06,3.76$ and $5.77 \mathrm{wt} . \% \mathrm{~min}^{-1}$ at $357,482,574$ and $664 \mathrm{~W}$, respectively, using the following equation:

$r_{\mathrm{avg}}=\eta_{\mathrm{ST} / \mathrm{SS}} /\left(t_{\mathrm{SS}}-t_{\mathrm{ST}}\right)$

Thus, a higher loading power gives higher decomposition efficiency and reaction rate. 
Table 2

The fractions of products of solid remained, liquid and gas from the pyrolysis of rice straw via RFPT-N system at reaction time of $45 \mathrm{~min}$ and various plateau temperatures $T_{\mathrm{P}}$ applying various loading powers $\mathrm{P}_{\mathrm{WL}}$.

\begin{tabular}{llll}
\hline$T_{\mathrm{P}}$ (or $\left.P_{\mathrm{WL}}\right)$ & $\begin{array}{l}\text { Solid remained }\left(M_{\mathrm{f}}\right) \\
(\text { wt.\%) }\end{array}$ & $\begin{array}{l}\text { Liquid products } \\
(\text { wt.\%) }\end{array}$ & $\begin{array}{l}\text { Gas products } \\
(\text { wt.\%) }\end{array}$ \\
\hline $740 \pm 5 \mathrm{~K}$ (or $357 \pm 2 \mathrm{~W})$ & 69.3 & 0 & 30.7 \\
$813 \pm 5 \mathrm{~K}$ (or $482 \pm 2 \mathrm{~W})$ & 43.4 & 0 & 56.6 \\
$843 \pm 5 \mathrm{~K}$ (or $574 \pm 2 \mathrm{~W})$ & 37.5 & 0 & 62.5 \\
$880 \pm 5 \mathrm{~K}$ (or $664 \pm 2 \mathrm{~W})$ & 33.5 & 0 & 66.5 \\
\hline
\end{tabular}

Initial mass of sample $W_{0}=300 \pm 10 \mathrm{mg}$, diameter of sample $d_{\mathrm{P}}=0.425-0.6 \mathrm{~mm}$, flow rate of carrier gas $Q=200 \mathrm{~mL} \mathrm{~min}^{-1}$ of $\mathrm{N}_{2}$.

\subsection{Fractions of products of solid, liquid and gas}

Table 2 lists the fractions of the products of solid residue $\mathrm{M}, \mathrm{li}$ quid and gas from the pyrolysis of rice straw via RFPT-N system at various loading powers $P_{\mathrm{WL}}$ and plateau temperatures $T_{\mathrm{P}}$. The values are expressed with respect to the initial mass of dried sample. According to the studies of Lin and Lin (2006) and Tu et al. (2008), the major mineral constituents of rice straw are $\mathrm{Si}, \mathrm{Al}, \mathrm{Na}, \mathrm{Mg}$ and Ca and the total content of oxide compounds of mineral matter is about $12.5 \mathrm{wt} . \%$ or $125,074.8 \mathrm{pp} \mathrm{mw}$, which is close to that of ash of $12.8 \mathrm{wt} . \%$.

From Table 2, the final residual mass fraction $M_{\mathrm{f}}$ at $45 \mathrm{~min}$ decreases as $T_{\mathrm{P}}$ and $P_{\mathrm{WL}}$ increase with $M_{\mathrm{f}}$ of $69.3,43.4,37.5$ and 33.5 wt.\% at $T_{\mathrm{P}}$ of $740,813,843$ and $880 \mathrm{~K}$, and $P_{\mathrm{WL}}$ of 357,482 , 574 and $664 \mathrm{~W}$, respectively. No liquid products were collected from the RFPT-N system in this study. This may be due to the causes that only a small amount of rice straw less than $3.5 \mathrm{wt} . \%$ was decomposed in the heating stage with temperature rise and that the energy species generated via RF plasma can enhance the decomposition of tar and complex compounds if they were produced. Therefore, one can derive that the pyrolyzed part of rice straw is transformed to the gas products. Thus, the corresponding fractions of gas products are 30.7, 56.6, 62.5 and $66.5 \mathrm{wt} . \%$, respectively. A higher loading power gives a higher plateau temperature and a larger amount of gas products.

\subsection{Characteristics of gas products and solid residues}

In order to examine the variation of concentration of gas products during the pyrolysis at various plateau temperatures $T_{\mathrm{P}}$ and loading powers $P_{\mathrm{WL}}$, the gas was sampled at different time intervals with $4 \mathrm{~min}$ per interval such as 1-5 min, 6-10 min and 11$15 \mathrm{~min}$ till $41-45 \mathrm{~min}$. Items of gas products analyzed included $\mathrm{H}_{2}, \mathrm{CO}, \mathrm{CH}_{4}$, non-methane hydrocarbons (NMHCs) and the total hydrocarbons (THCs). The concentrations of NMHCs and THCs are expressed as $\mathrm{CH}_{4}$ equivalence. The value of NMHCs is the difference between the values of THCs and $\mathrm{CH}_{4}$. Fig. 3 shows the instantaneous concentrations of gas products. The results indicated that the gas production is negligible in the heating period with temperature rise before reaching the setting temperature $T_{\mathrm{ST}}$ at time $t_{\mathrm{ST}}$. After $t_{\mathrm{ST}}$, gases are produced significantly as the pyrolysis proceeds vigorously at $T_{\mathrm{P}}$ with a higher $T_{\mathrm{P}}$ yielding more gases production as expected. The production of gases then reduces as the residual mass fraction $M$ decreases approaching its final value $M_{\mathrm{f}}$ as shown in Fig. 2a. The maximum concentrations of various gas products appear earlier for higher $T_{\mathrm{P}}$ or $P_{\mathrm{WL}}$. The characteristics of gas products measured via GC-FID indicated that the major constituents of NMHCs are hydrocarbons of $C_{2}-C_{5}$. The accumulated amounts of gas products $W_{\mathrm{G}, \mathrm{Acc}}$ in weight including $\mathrm{H}_{2}, \mathrm{CO}, \mathrm{CH}_{4}$ and NMHCs at various $T_{\mathrm{P}}$ or $P_{\mathrm{WL}}$ are shown in Fig. 4 . At $45 \mathrm{~min}$, the values of $W_{\mathrm{G}, \text { Acc }}$ symboled as $W_{\mathrm{G}, \text { Acc, } \mathrm{f}}$ at various $P_{\mathrm{WL}}$ of $357,482,574$ and $664 \mathrm{~W}$ are $90.11,147.2,184.39$ and $192.08 \mathrm{mg}$, respectively. More- over, Fig. 4 shows that the linear gas producing rates of the middle portions are $6.01,7.36,7.38$ and $7.68 \mathrm{mg} \mathrm{min}^{-1}$ at $P_{\mathrm{WL}}$ of 357,482 , 574 and $664 \mathrm{~W}$, respectively. A higher $P_{\mathrm{WL}}$ can shorten the heating time for the production of gas products and give a higher $T_{\mathrm{P}}$ favourable to the pyrolytic reaction, thus resulting in a larger production of gas products with a higher producing rate. The yields and volume fraction contents of different component i denoted as $Y_{\mathrm{W}, \mathrm{i}}$ and $V_{\mathrm{i}}$ are listed in Table 3 . As $T_{\mathrm{P}}$ increases from 740 to $880 \mathrm{~K}$ sum of the yields of $\mathrm{CO}$ and $\mathrm{H}_{2}$ of syngas increases greatly from 29.08 to 62.42 wt.\%. Further, on nitrogen free basis, the volume fractions of syngas consisting of $\mathrm{CO}$ and $\mathrm{H}_{2}$ are all above $97 \mathrm{vol} . \%$ for the four cases examined. Table 3 also gives the sums of yields of all gas products collected with values of 30.04, 49.07, 61.47 and $64.03 \mathrm{wt} . \%$ at $T_{\mathrm{P}}$ of $740,813,843$ and $880 \mathrm{~K}$, respectively. These values are close to the predicted values of 30.7, 56.6, 62.5 and $66.5 \mathrm{wt} . \%$ as listed in Table 2 . Thus, the recoveries of gas products $R_{\mathrm{CG}}$ are about $98,87,98$ and $96 \%$ for the cases with $T_{\mathrm{P}}$ of 740,813 , 843 and $880 \mathrm{~K}$, respectively. Note that $R_{\mathrm{CG}}$ can also be estimated using the following equation:

$R_{\mathrm{CG}}=W_{G, \mathrm{Acc}, \mathrm{f}} /\left[W_{0} \times\left(1-M_{\mathrm{f}}\right)\right]$

Table 4 lists the BET surface area and element constituents of the solid residues at various $T_{\mathrm{p}}$ via RFPT-N system. The BET surface area increases from that of the original rice straw of $1.21 \mathrm{~m}^{2} \mathrm{~g}^{-1}$ to those of solid residues $2.11,5.60,5.86$ and $6.50 \mathrm{~m}^{2} \mathrm{~g}^{-1}$ at $T_{\mathrm{P}}$ of 740,813 , 843 and $880 \mathrm{~K}$, respectively. The feature of high heating rate HR of RFPT-N system is beneficial for reducing the formation of tar, while enhancing the production of gases of low molecular weights such as $\mathrm{C}_{2}-\mathrm{C}_{5}$ of hydrocarbons. However, the high HR of RFPT-N system may not provide enough time for the formation and development of pore structure of carbonaceous solid residues which although still contain about $42-50$ wt.\% of carbon. The common HR for the formation of pore structure of carbonaceous solid residues is about 5-20 K min ${ }^{-1}$ (Tsai et al., 2001). Thus, the BET surface area of the solid residues via RFPT-N system is inferior.

\subsection{The kinetic model of combustible solid residues at constant temperature}

Fig. 5 shows the time variation of residual mass fraction symboled as $M_{\mathrm{STF}}$ after the heating time $t_{\mathrm{ST}}$ based on the total amount of mass pyrolyzed, which is denoted as $W_{\mathrm{STF}}$, at various loading powers $P_{\mathrm{WL}}$. The $M_{\mathrm{STF}}$ and $W_{\mathrm{STF}}$ are defined as

$M_{\mathrm{STF}}=\left(W-W_{\mathrm{f}}\right) / W_{\mathrm{STF}}$

$W_{\mathrm{STF}}=W_{\mathrm{ST}}-W_{\mathrm{f}}$

In Eqs. (7) and (8), $W$ and $W_{\mathrm{f}}$ are the present and final masses of samples defined in the proceeding sections, $W_{\mathrm{ST}}$ is the mass of sample at $t_{\mathrm{ST}}$ or at the setting temperature $\mathrm{T}_{\mathrm{ST}}$. The values of $M_{\mathrm{STF}}$ are nearly constant after $35.5,15.83,11$ and $6.17 \mathrm{~min}$ for the cases with $P_{\mathrm{WL}}$ of $357,482,574$ and $664 \mathrm{~W}$, respectively. The reaction rate equation is proposed for the $M_{\mathrm{STF}}$ as

$\mathrm{dM}_{\mathrm{STF}} / d\left(t-t_{\mathrm{ST}}\right)=-k M_{\mathrm{STF}}^{n}$

which gives

$M_{\mathrm{STF}}=\left[1-(-n+1) k\left(t-t_{\mathrm{ST}}\right)\right]^{[1 /(-n+1)]}$

where $\mathrm{n}$ is the reaction order and $k$ is the reaction rate constant described by Arrhenius equation as $k=A \exp \left(-E a / R_{G} T\right)$ with $A, E a$ and $R_{G}$ representing the frequency factor, activation energy and universal gas constant (Huang et al., 2004). The best curve fittings render $A$ of $5759.5 \mathrm{~s}^{-1}$, Ea of $74.29 \mathrm{~kJ} \mathrm{~mol}^{-1}$ and $\mathrm{n}$ of 0.5 . Fig. $5 \mathrm{com}-$ pares the experimental data and the predicted results. The coefficients of determination $R^{2}$ are $0.973,0.995,0.997$ and 0.963 for the cases with $P_{\mathrm{WL}}$ of $357,482,574$ and $664 \mathrm{~W}$, respectively. The 

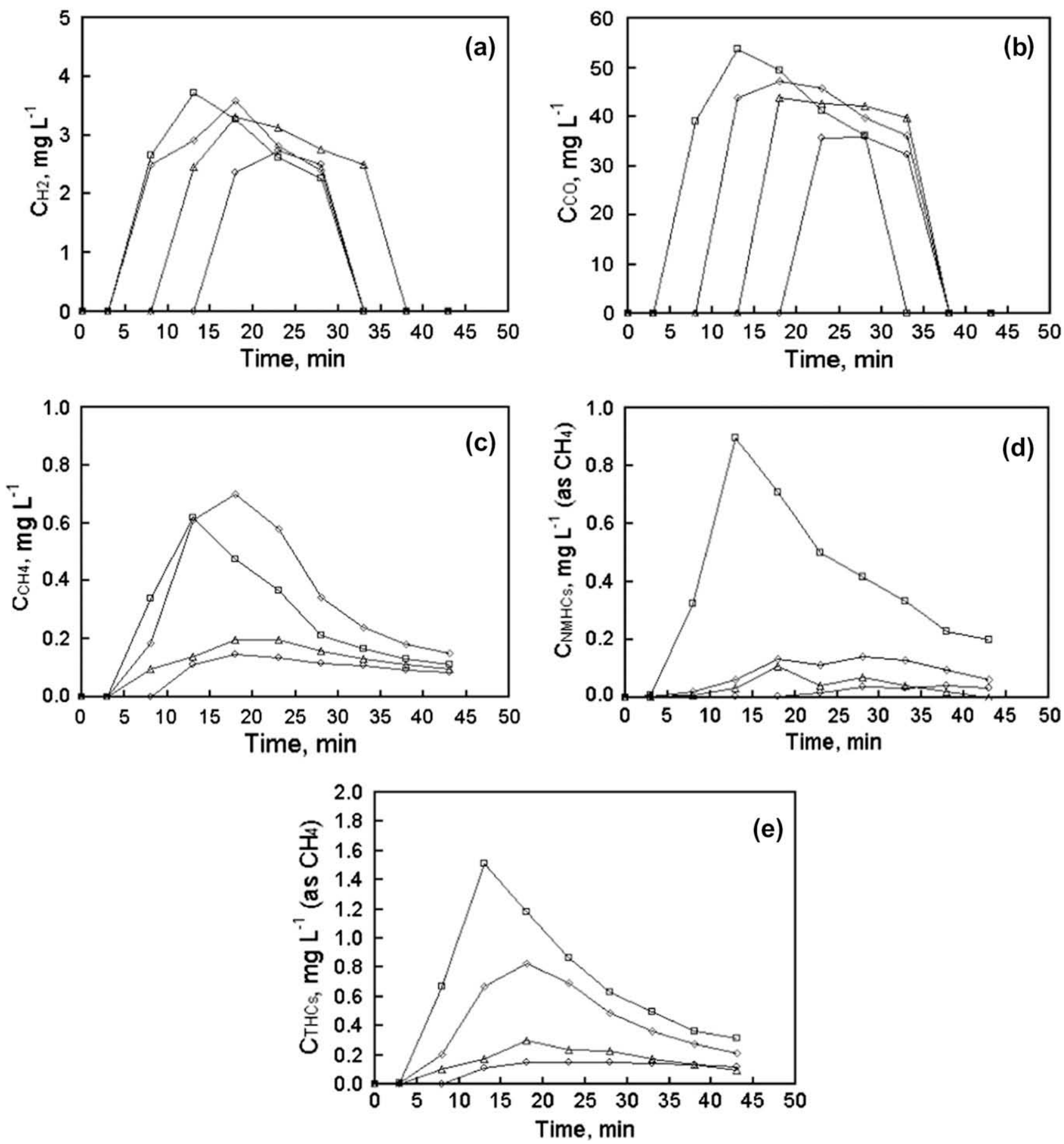

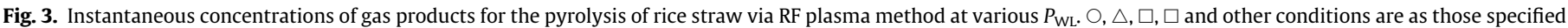
in Fig. 2. (a) $\mathrm{H}_{2}$, (b) $\mathrm{CO}$, (c) $\mathrm{CH}_{4}$, (d) non-methane hydrocarbons (NMHCs), (e) total HCs (THCs).

good agreement between the two indicates that this model can be employed to describe the pyrolytic conversion of rice straw at constant temperatures.

3.5. The energy consumption and recovery and the heating values in the original sample and all products

The pyrolysis of rice straw via RF plasma can produce usable gas products not only as resources but also as energy with their corresponding specific heating values $H_{\mathrm{V}}$. Table 5 lists the values of $H_{\mathrm{V}}$ of gas and solid products obtained at various plateau temperatures $T_{\mathrm{P}}$ applying various loading powers $P_{\mathrm{WL}}$. The specific heating values gained from the gas products denoted as $H_{\mathrm{V}, \mathrm{G}}$ are estimated via dividing the sum of all heating values of the corresponding combustible components by the total amount of gas products. The results are $4548,4284,4469$ and $4438 \mathrm{kcal} \mathrm{kg}^{-1}$ for the cases with $T_{\mathrm{P}}$ of $740,813,843$ and $880 \mathrm{~K}$, respectively.

The $H_{\mathrm{V}}$ of each residual solid symboled as $H_{\mathrm{V}, \mathrm{S}}$ was calculated employing the Scheurer-Kestner formula, noted as S-K formula, using the element constituents in each residual solid listed in 


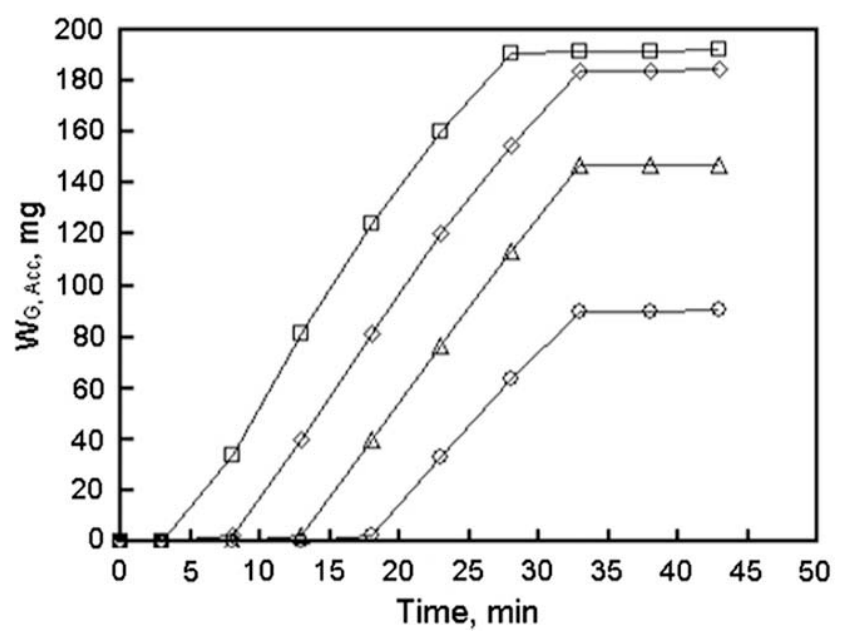

Fig. 4. Accumulated amounts of gas products $\left(W_{\mathrm{G}, \mathrm{Acc}}\right)$ of $\mathrm{H}_{2}, \mathrm{CO}, \mathrm{CH}_{4}$ and $\mathrm{NMHCs}$ collected for the pyrolysis of rice straw via RF plasma method at various $P_{\mathrm{WL}^{*}}(\bigcirc)$, $(\triangle),(\square),(\diamond)$ and other conditions are as those specified in Fig. 2.

Table 4. The actual $H_{\mathrm{V}, \mathrm{S}}$ of original rice straw was also measured using the adiabatic bomb calorimeter, giving the value of $4042 \mathrm{kcal}$ $\mathrm{kg}^{-1}$ close to the theoretical $H_{\mathrm{V}, \mathrm{S}}$ of $4154 \mathrm{kcal} \mathrm{kg}^{-1}$ calculated with $\mathrm{S}-\mathrm{K}$ formula. The less than 3\% difference between these two values supports the validity of using the S-K formula to estimate the $H_{\mathrm{V}, \mathrm{S}}$ of solid samples. The $\mathrm{S}-\mathrm{K}$ formula is as follows.

S-K formula:

$H_{V, S}=81\left(C-\frac{3}{4} \mathrm{O}\right)+342.5 H+22.5 S+57 \times\left(\frac{3}{4} \mathrm{O}\right)-6\left(9 H+W_{\mathrm{H}_{2} \mathrm{O}}\right)$

in which, the $\mathrm{C}, \mathrm{O}, \mathrm{H}$ and $\mathrm{S}$ represent the percent contents of elements of sample in wt.\% and $W_{\mathrm{H}_{2} \mathrm{O}}$ is the moisture content of sample in wt.\%. The numbers of $81,342.522 .5$ and 57 are the heats of combustion of $\mathrm{C}$ to $\mathrm{CO}_{2}, \mathrm{H}$ to $\mathrm{H}_{2} \mathrm{O}, \mathrm{S}$ to $\mathrm{SO}_{2}$ and $\mathrm{C}$ to $\mathrm{CO}$, respectively, in $\mathrm{kcal} \mathrm{kg}^{-1}$. The number of 6 is the heat of evaporation of water transfer to gaseous $\mathrm{H}_{2} \mathrm{O}$ in $\mathrm{kcal} \mathrm{kg}^{-1}$. The numbers of $3 / 4$ and 9 are the ratios of molecular weights of $\mathrm{C}$ to $\mathrm{O}$ and $\mathrm{H}_{2} \mathrm{O}$ to $\mathrm{H}_{2}$, respectively. The masses of $\mathrm{S}$ and moisture content of the samples are low and can be neglected. Thus, also for the said cases, the corresponding combustible portions remained in the solid residues are 64.7, 35, 28.2 and $23.5 \mathrm{wt} . \%$ with $H_{\mathrm{V}, \mathrm{S}}$ of $4106,4438,4328$ and $4251 \mathrm{kcal}$ $\mathrm{kg}^{-1}$ with respect to the solid residues, respectively. The original dried sample contains 87.2 wt.\% combustibles with $H_{\mathrm{V}, \mathrm{S}}$ of $4042 \mathrm{kcal} \mathrm{kg}^{-1}$ as already noted. The values of $H_{\mathrm{V}, \mathrm{S}}$ and $H_{\mathrm{V}, \mathrm{G}}$ of solid residues and gas products show small variation. However, the values of $H_{\mathrm{V}, \mathrm{G}} \times\left(W_{0}-W_{\mathrm{f}}\right)$ of gas products, representing the total heating values gained in gas products, are 418.9, 727.4, 838 and $885.3 \mathrm{cal}$ for the corresponding cases, respectively, which increase as $T_{\mathrm{P}}$ increases. The results indicated that the amount of combustibles converted into gas products increases with increasing $T_{\mathrm{P}}$ as expected.

The specific total heating value of solid and gas products denoted as $H_{\mathrm{V}, \mathrm{T}}$ increases from 4042 of original dried rice straw to about $4242,4351,4416$ and $4375 \mathrm{kcal} \mathrm{kg}^{-1}$ at $T_{\mathrm{P}}$ of $740,813,843$ and $880 \mathrm{~K}$ with corresponding $P_{\mathrm{WL}}$ of $357,482,574$ and $664 \mathrm{~W}$, respectively, as shown in Table 5 . The total heating values noted as $H_{\mathrm{V}, \mathrm{T}} \times W_{0}$ are then calculated to be $1.21 \mathrm{kcal}$ of original dried rice straw and 1.27, 1.31, 1.33 and $1.31 \mathrm{kcal}$ for the pyrolytic products of rice straw respectively, as listed in Table 6 . The energies consumed in the temperature-rising heating period of $t_{\mathrm{ST}}$ denoted as $E_{\mathrm{ST}}$ are about $0.08,0.1,0.12$ and $0.13 \mathrm{kcal}$, and the corresponding energies consumed at the constant-temperature heating period at $T_{\mathrm{P}}$ to reach steady state symboled as $E_{\mathrm{TP}}$ are about $0.64,0.63,0.46$ and $0.37 \mathrm{kcal}$. Note that the amount of rice straw sample $W_{0}$ charged in the RFPT-N system for the pyrolysis experiments was about $0.3 \mathrm{~g}$, while the allowable loading capacity $W_{\mathrm{a}}$ of the reactor is $85.12 \mathrm{~g}$. Therefore, the values of $E_{\mathrm{ST}}$ and $E_{\mathrm{TP}}$ consumed by $W_{0}$ are computed as a fraction $W_{0} / W_{\mathrm{a}}$ of the energies input in the corresponding heating periods. The bulk density of rice straw in this study of $0.2 \pm 0.01 \mathrm{~g} \mathrm{~cm}^{-3}$ was determined according to the procedures of Pendyal et al. (1999). The allowable batch amount of rice straw that can be treated in RFPT-N system is estimated considering the inner diameter of plasma reactor of $46 \mathrm{~mm}$, length of plasma zone of $320 \mathrm{~mm}$, bulk density of rice straw of $0.2 \pm 0.01 \mathrm{~g} \mathrm{~cm}^{-3}$ and percent of usage of capacity of plasma reactor of $80 \mathrm{vol} . \%$. This then gives the allowable loading capacity of rice straw of about $85.12 \mathrm{~g}$. In obtaining $H_{\mathrm{V}, \mathrm{T}}, E_{\mathrm{ST}}$ and $E_{\mathrm{TP}}$, the applicable equations are as follows.

$H_{\mathrm{V}, \mathrm{T}}=H_{\mathrm{V}, \mathrm{S}} \times M_{\mathrm{f}}+H_{\mathrm{V}, \mathrm{G}} \times\left(1-M_{\mathrm{f}}\right)$, in $\mathrm{kcal} \mathrm{kg}^{-1}$

$E_{\mathrm{ST}}=\left[\left(P_{\mathrm{WL}} \times t_{\mathrm{ST}} \times 60\right) / 4.1868\right] \times\left(W_{0} / W_{\mathrm{a}}\right)$, in cal

$E_{\mathrm{TP}}=\left[P_{\mathrm{WL}} \times\left(t_{\mathrm{SS}}-t_{\mathrm{ST}}\right) \times 60\right] / 4.1868 \times\left(W_{0} / W_{\mathrm{a}}\right)$, in cal

Table 6 lists the energy recoveries $R_{\mathrm{E}, \text { all }}$ of the entire process including temperature-rising and constant-temperature heating periods for the pyrolysis of rice straw via RFPT-N system, giving 0.66, $0.68,0.74$ and 0.77 at $P_{\mathrm{WL}}$ of $357,482,574$ and $664 \mathrm{~W}$, respectively. The corresponding energy recoveries $R_{\mathrm{E}, \mathrm{TP}}$ of the process considering constant-temperature heating at the $T_{P}$ are also presented in Table 6 with values of $0.69,0.71,0.8$ and 0.83 , respectively. The results indicated that the energy recovery increases as $P_{\mathrm{WL}}$ increases, suggesting that the pyrolysis via RF plasma is favorable applying a higher $P_{\mathrm{WL}}$. In estimating $R_{\mathrm{E}, \text { all }}$ and $R_{\mathrm{E}, \mathrm{TP}}$, the following equations are employed.

$R_{\mathrm{E}, \mathrm{all}}=\left(H_{\mathrm{V}, \mathrm{T}} \times W_{0}\right) /\left[1.21+\left(E_{\mathrm{ST}}+E_{\mathrm{TP}}\right)\right]$

$R_{E, \mathrm{TP}}=\left(H_{\mathrm{V}, \mathrm{T}} \times W_{0}\right) /\left(1.21+E_{\mathrm{TP}}\right)$

Table 3

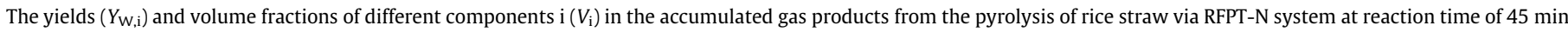
and various $T_{\mathrm{P}}$ applying various $P_{\mathrm{WL}}$.

\begin{tabular}{|c|c|c|c|c|c|c|c|c|c|}
\hline$T_{\mathrm{P}}\left(\right.$ or $\left.P_{\mathrm{WL}}\right)$ & $Y_{\mathrm{W}, \mathrm{co}}(\mathrm{wt} . \%)$ & $Y_{\mathrm{W}, \mathrm{H} 2}(\mathrm{wt} . \%)$ & $Y_{\mathrm{W}, \mathrm{CH} 4}(\mathrm{wt} . \%)$ & $Y_{\mathrm{W}, \mathrm{NMHCs}}(\mathrm{wt} . \%)$ & $Y_{\mathrm{W}, \mathrm{G}}^{\mathrm{a}}$ (wt.\%) & $V_{\mathrm{CO}}(\mathrm{vol} . \%)$ & $V_{\mathrm{H}_{2} \mathrm{O}}(\mathrm{vol} . \%)$ & $V_{\mathrm{CH}_{4}}(\mathrm{vol} . \%)$ & $V_{\mathrm{NMHCs}}(\mathrm{vol} . \%)$ \\
\hline $740 \pm 5 \mathrm{~K}($ or $357 \pm 2 \mathrm{~W})$ & $27.75^{\mathrm{b}}$ & $2.03^{\mathrm{b}}$ & $0.21^{\mathrm{b}}$ & $0.05^{\mathrm{b}}$ & $30.04^{\mathrm{b}}$ & $92.39^{c}(1.01)^{d}$ & $6.75^{c}(0.07)^{d}$ & $0.71^{\mathrm{c}}(0.008)^{\mathrm{d}}$ & $0.16^{c}(0.002)^{d}$ \\
\hline $813 \pm 5 \mathrm{~K}($ or $482 \pm 2 \mathrm{~W})$ & 44.9 & 3.78 & 0.3 & 0.09 & 49.07 & $91.51(1.63)$ & $7.70(0.14)$ & $0.61(0.011)$ & $0.18(0.003)$ \\
\hline $843 \pm 5 \mathrm{~K}($ or $574 \pm 2 \mathrm{~W})$ & 56.68 & 3.79 & 0.8 & 0.2 & 61.47 & $92.21(2.06)$ & $6.16(0.14)$ & $1.29(0.029)$ & $0.33(0.007)$ \\
\hline $880 \pm 5 \mathrm{~K}($ or $664 \pm 2 \mathrm{~W})$ & 58.54 & 3.88 & 0.65 & 0.96 & 64.03 & $91.43(2.13)$ & $6.06(0.14)$ & $1.01(0.024)$ & $1.51(0.035)$ \\
\hline
\end{tabular}

\footnotetext{
$Y_{\mathrm{W}, \mathrm{G}}=Y_{\mathrm{W}, \mathrm{CO}}+Y_{\mathrm{W}, \mathrm{H} 2}+Y_{\mathrm{W}, \mathrm{CH} 4}+Y_{\mathrm{W}, \mathrm{NMHCs}}$.

b With respect to the original dried sample.

c On nitrogen free basis.

d On nitrogen basis.
} 
Table 4

The BET surface area denoted as $A_{\mathrm{BET}}$ and element analyses of solid residues from the pyrolysis of rice straw via RFPT-N system at reaction time of $45 \mathrm{~min}$ and various $T_{\mathrm{P}}$ applying various $P_{\mathrm{WL}}$.

\begin{tabular}{clllllll}
\hline$T_{\mathrm{P}}\left(\right.$ or $\left.P_{\mathrm{WL}}\right)$ & $\begin{array}{l}A_{\mathrm{BET}} \\
\left(\mathrm{m}^{2} \mathrm{~g}^{-1}\right)\end{array}$ & $\begin{array}{l}\mathrm{C} \\
(\mathrm{wt} . \%)\end{array}$ & $\begin{array}{l}\mathrm{H} \\
(\mathrm{wt} . \%)\end{array}$ & $\begin{array}{l}\mathrm{N} \\
(\mathrm{wt} . \%)\end{array}$ & $\begin{array}{l}\mathrm{O}^{\mathrm{a}} \\
(\mathrm{wt} . \%)\end{array}$ & $\begin{array}{l}\mathrm{S} \\
(\mathrm{wt} . \%)\end{array}$ & $\begin{array}{l}\mathrm{Cl} \\
(\mathrm{wt} . \%)\end{array}$ \\
\hline $\begin{array}{c}\text { Original rice } \\
\text { straw }\end{array}$ & 1.21 & 41.8 & 5.9 & 0.4 & 51.6 & 0.2 & 0.1 \\
$\begin{array}{c}740 \pm 5 \mathrm{~K} \text { (or } \\
\quad 2.11\end{array}$ & 42.6 & 5.5 & 0.5 & 51.4 & - & - \\
$\begin{array}{c}357 \pm 2 \mathrm{~W}) \\
813 \pm 5 \mathrm{~K} \text { (or } \\
\quad 582 \pm 2 \mathrm{~W})\end{array}$ & 5.60 & 49.8 & 4.3 & 0.8 & 45.1 & - & - \\
$\begin{array}{c}843 \pm 5 \mathrm{~K}(\text { or } \\
574 \pm 2 \mathrm{~W})\end{array}$ & 5.86 & 48.9 & 4.2 & 0.8 & 46.1 & - & - \\
$\begin{array}{c}880 \pm 5 \mathrm{~K}(\text { or } \\
664 \pm 2 \mathrm{~W})\end{array}$ & 6.50 & 49.4 & 3.8 & 0.7 & 46.1 & - & - \\
\hline
\end{tabular}

-: Neglected and not measured.

a Balance.

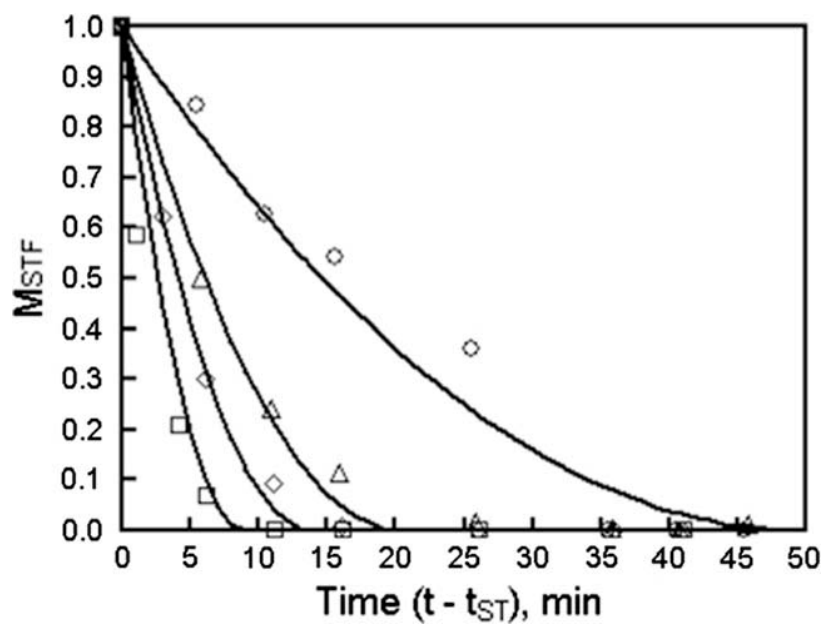

Fig. 5. Time variations of $M_{\mathrm{STF}}$ after $t_{\mathrm{ST}}$ for the pyrolysis of rice straw via RF plasma method at various $P_{\mathrm{WL}} . M_{\mathrm{f}}=69.3,43.4,37.5$ and $33.5, t_{\mathrm{ST}}=4.5,4.17,4$ and $3.83 \mathrm{~min}$, and $R^{2}=0.973,0.995,0.997$ and 0.963 for $\mathrm{P}_{\mathrm{WL}}=357,482,574$ and $664 \mathrm{~W}$, respectively. $n=0.5$. Symbols and lines: Experimental data and prediction. $\mathrm{M}_{\mathrm{STF}}$ : Residual mass fraction based on total amount of mass pyrolyzed, $=\left(W-W_{\mathrm{f}}\right) /\left(W_{\mathrm{ST}}-\right.$ $\left.W_{\mathrm{f}}\right) . W, W_{\mathrm{f}}$ : Present and final masses of samples. $W_{\mathrm{ST}}$ : Mass of sample at heating time $t_{\mathrm{ST}}$ reaching setting temperature. $R^{2}$ : Coefficient of determination. $\mathrm{n}$ : Reaction order. $(\bigcirc),(\triangle),(\square),(\diamond)$ and other conditions are as those specified in Fig. 2.

Table 5

The specific heating values $\left(H_{\mathrm{V}}\right)$ of original sample and all products from the pyrolysis of rice straw via RFPT-N system at reaction time of $45 \mathrm{~min}$ and various $T_{\mathrm{P}}$ applying various $P_{\mathrm{WL}}$.

\begin{tabular}{llll}
\hline$T_{\mathrm{P}}$ (or $\left.P_{\mathrm{WL}}\right)$ & $\begin{array}{l}\mathrm{H}_{\mathrm{V}, \mathrm{S}} \\
\left(\mathrm{kcal} \mathrm{kg}^{-1}\right)\end{array}$ & $\begin{array}{l}\mathrm{H}_{\mathrm{V}, \mathrm{G}} \\
\left(\mathrm{kcal} \mathrm{kg}^{-1}\right)\end{array}$ & $\begin{array}{l}H_{\mathrm{V}, \mathrm{T}} \\
\left(\mathrm{kcal} \mathrm{kg}^{-1}\right)\end{array}$ \\
\hline Original rice straw (actual) & 4042 & $\mathrm{NA}$ & 4042 \\
Original rice straw (theoretical) & 4154 & $\mathrm{NA}$ & 4154 \\
$740 \pm 5 \mathrm{~K}$ (or $357 \pm 2 \mathrm{~W})$ & 4106 & 4548 & 4242 \\
$813 \pm 5 \mathrm{~K}$ (or $482 \pm 2 \mathrm{~W})$ & 4438 & 4284 & 4351 \\
$843 \pm 5 \mathrm{~K}$ (or 574 $\pm 2 \mathrm{~W})$ & 4328 & 4469 & 4416 \\
$880 \pm 5 \mathrm{~K}$ (or 664 $\pm 2 \mathrm{~W})$ & 4251 & 4438 & 4375 \\
\hline
\end{tabular}

$H_{\mathrm{V}, \mathrm{S}}$ and $H_{\mathrm{V}, \mathrm{G}}$ : Specific heating values of solid residues and gas products, respectively.

$H_{\mathrm{V}, \mathrm{T}}$ : Specific total heating value of solid and gas products from pyrolysis, $=H_{\mathrm{V}, \mathrm{S}} \times$ $M_{\mathrm{f}}+H_{\mathrm{V}, \mathrm{G}} \times\left(1-M_{\mathrm{f}}\right)$.

$H_{\mathrm{V}, \mathrm{T}}$ of original rice straw: same as $H_{\mathrm{V}, \mathrm{S}}$.

$H_{\mathrm{V}, \mathrm{CO}}, H_{\mathrm{V}, \mathrm{H} 2}, H_{\mathrm{V}, \mathrm{CH} 4}$ and $H_{\mathrm{V}, \mathrm{NMHCs}}=282.99,285.84,890.35$ and $890.35 \mathrm{~kJ} \mathrm{~mol}^{-1}=$ 2413, 34136, 13291 and $13291 \mathrm{kcal} \mathrm{kg}^{-1}$.

NA: Not applicable.
Table 6

The energy consumption and recovery and heating values of all products from the pyrolysis of rice straw via RFPT-N system at reaction time of $45 \mathrm{~min}$ applying various $P_{\mathrm{WL}}$

\begin{tabular}{llllll}
\hline$P_{\mathrm{WL}}$ & $H_{\mathrm{V}, \mathrm{T}} \times W_{0}(\mathrm{kcal})$ & $E_{\mathrm{ST}}(\mathrm{kcal})$ & $E_{\mathrm{TP}}(\mathrm{kcal})$ & $R_{\mathrm{E}, \text { all }}$ & $R_{\mathrm{E}, \mathrm{TP}}$ \\
\hline $357 \mathrm{~W}$ & 1.27 & 0.08 & 0.64 & 0.66 & 0.69 \\
$482 \mathrm{~W}$ & 1.31 & 0.1 & 0.63 & 0.68 & 0.71 \\
$574 \mathrm{~W}$ & 1.33 & 0.12 & 0.46 & 0.74 & 0.8 \\
$664 \mathrm{~W}$ & 1.31 & 0.13 & 0.37 & 0.77 & 0.83
\end{tabular}

$H_{\mathrm{T}, \mathrm{V}}$ : Specific heating value with unit in $\mathrm{kcal} \mathrm{kg}^{-1}$

$W_{0}$ : Mass of sample, $=0.3 \times 10^{-3} \mathrm{~kg}$.

$H_{\mathrm{V}, \mathrm{T}} \times W_{0}$ of original rice straw: $1.21 \mathrm{kcal}$.

$E_{\mathrm{ST}}$ : Energy consumed in temperature-rising heating period of $t_{\mathrm{ST}}$.

$E_{\mathrm{TP}}$ : Energy consumed at constant-temperature heating at $\mathrm{T}_{\mathrm{P}}$ to reach steady state of solid residues.

$R_{\mathrm{E}, \text { all }}$ : Energy recovery ratio of the entire process including temperature-rising and constant-temperature heating periods as calculated using Eq. (15).

$R_{\mathrm{E}, \mathrm{TP}}$ : Energy recovery ratio of the process considering constant-temperature heating at $T_{\mathrm{P}}$ as computed using Eq. (16).

\section{Conclusions}

The RFPT-N system overcomes the problem of tar formation during the pyrolysis of rice straw. In this system, a higher loading power gives a higher plateau temperature with a shorter heating time to reach setting temperature. The high heating rate of RF plasma can efficiently decompose the combustible solid to gas products of $\mathrm{H}_{2}, \mathrm{CO}, \mathrm{CH}_{4}$ and low carbon hydrocarbons such as $\mathrm{C}_{2}-\mathrm{C}_{5}$. The production of gases increases as the pyrolysis is proceeded vigorously at a higher plateau temperature. Also, an increase in loading power increases the total heating value of the products of gas and solid residues.

The kinetic model employed to describe the pyrolytic conversion of rice straw at constant temperature agrees well with the experimental data. The frequency factor, activation energy and reaction order are $5759.5 \mathrm{~s}^{-1}, 74.29 \mathrm{~kJ} \mathrm{~mol}^{-1}$ and 0.5 , respectively. The obtained data and information are useful for the rational operation and design of pyrolysis of rice straw via RF plasma.

The energy recovery from the pyrolysis of rice straw via RFPT-N system increases with increasing loading power. In practical, the rice straw can be pre-treated via pelletization to prepare the refuse derived fuel before being charged into the reactor. This can increase the density of rice straw pellet and the capacity of loading, enhancing the energy utilization efficiency.

\section{Acknowledgement}

We express our sincere thanks to the National Science Council of Taiwan for the financial support, under the contract No. NSC95-2218-E-002-035.

\section{Appendix Notations. and abbreviations}

A Frequency factor, $\mathrm{s}^{-1}$

BET Brunauer-Emmett-Teller

$d_{\mathrm{P}} \quad$ Diameter of sample, $\mathrm{mm}$

$E_{\mathrm{a}} \quad$ Activation energy, $\mathrm{kJ} \mathrm{mol}^{-1}$

$E_{\mathrm{ST}} \quad$ Energy consumed in temperature-rising heating period of $t_{\mathrm{ST}}$, kcal

$E_{\mathrm{TP}} \quad$ Energy consumed at constant-temperature heating at $T_{\mathrm{P}}$ to reach steady state of solid residues, kcal

$H_{\mathrm{V}} \quad$ Specific heating value, $\mathrm{kcal} \mathrm{kg}^{-1}$

$H_{\mathrm{V}, \mathrm{G}} \quad H_{\mathrm{V}}$ of gas products, $\mathrm{kcal}_{\mathrm{kg}}^{-1}$

$H_{\mathrm{V}, \mathrm{S}} \quad H_{\mathrm{V}}$ of solid residues, $\mathrm{kcal} \mathrm{kg}^{-1}$ 
$H_{\mathrm{V}, \mathrm{T}} \quad$ Specific total heating value of solid and gas products, = $H_{\mathrm{V}, \mathrm{S}} \times M_{\mathrm{f}}+H_{\mathrm{V}, \mathrm{G}} \times\left(1-M_{\mathrm{f}}\right), \mathrm{kcal} \mathrm{kg}^{-1}$

HR Heating rate, $K$ min $^{-1}$

$k \quad$ Reaction rate constant, $=A \exp \left(-E a / R_{G} T\right), \mathrm{s}^{-1}$

$M \quad$ Residual mass fraction defined in Eq. (1), = W/W

$M_{\mathrm{f}} \quad$ Final value of $\mathrm{M}$ at $45 \mathrm{~min}$, -

$M_{\mathrm{SS}} \quad$ Value of $M$ at $t_{\mathrm{SS}}$ -

$M_{\mathrm{ST}} \quad$ Value of $M$ at $T_{\mathrm{ST}}$ or $t_{\mathrm{ST},}-$

$M_{\mathrm{STF}} \quad$ Residual mass fraction after $t_{\mathrm{ST}}$ based on $W_{\mathrm{STF}},=(W-$ $\left.W_{\mathrm{f}}\right) / W_{\mathrm{STF}},-$

NMHCs Non-methane hydrocarbons

$n \quad$ Reaction order, -

$P \quad$ Final pressure, Torr

$P_{0} \quad$ Initial pressure, Torr

$P_{\mathrm{WI}} \quad$ Input power, $W$

$P_{\mathrm{WL}} \quad$ Loading power, $=P_{\mathrm{WI}}-P_{\mathrm{WR}}, W$

$P_{\mathrm{WR}} \quad$ Reflected power, $W$

$Q \quad$ Flow rate of carrier gas, $\mathrm{mL} \mathrm{min}^{-1}$

$R^{2} \quad$ Coefficient of determination, $=1-\left[\sum\left(y_{\mathrm{e}}-y_{\mathrm{p}}\right)^{2} / \sum\left(y_{\mathrm{e}}-\right.\right.$ $\left.\left.y_{\mathrm{e}, \text { Average }}\right)^{2}\right],-$

$R_{\mathrm{CG}} \quad$ Recovery of gas products estimated using Eq. (6), wt.\%

$R_{\mathrm{E}, \text { all }} \quad$ Energy recovery ratio of the entire process including temperature-rising and constant-temperature heating periods as calculated using Eq. (15),-

$R_{\mathrm{E}, \mathrm{TP}} \quad$ Energy recovery ratio of the process considering constant-temperature heating at $\mathrm{T}_{\mathrm{P}}$ as computed using Eq. (16), -

$R_{\mathrm{G}} \quad$ Universal gas constant, $0.008314 \mathrm{~kJ} \mathrm{~K}^{-1} \mathrm{~mol}^{-1}$

RF Radio frequency

RFPT RF Plasma pyrolysis (thermolysis)

RFPT-N Modified RFPT

$r_{\text {avg }} \quad$ Average reaction rate during $t_{\mathrm{ST}}$ to $t_{\mathrm{SS}}$ as calculated using Eq. (5), wt.\% $\min ^{-1}$

$T_{\mathrm{P}} \quad$ Plateau temperature, $\mathrm{K}$

$T_{\mathrm{r}} \quad$ Reaction temperature, $\mathrm{K}$

$T_{\mathrm{ST}} \quad$ Setting temperature, $=\mathrm{T}_{0}+0.95\left(\mathrm{~T}_{\mathrm{P}}-\mathrm{T}_{0}\right), \mathrm{K}$

$T_{0} \quad$ Initial or room temperature, $\mathrm{K}$

THCs Total hydrocarbons

$t_{\mathrm{H}} \quad$ Heating time, min

$t_{\mathrm{SS}} \quad$ Heating time to reach steady state, min

$t_{\mathrm{ST}} \quad$ Heating time to reach $T_{\mathrm{ST}}$, min

$V_{\mathrm{i}} \quad$ Volume fraction of component $\mathrm{i}$ in the accumulated gas products, vol.\%

W Present mass of sample, mg

$W_{0} \quad$ Initial mass of sample, $\mathrm{mg}$

$W_{\mathrm{a}} \quad$ Allowable loading capacity of the reactor, $\mathrm{g}$

$W_{\mathrm{f}} \quad$ Final mass of sample after 45 min reaction, $\mathrm{mg}$

$W_{\mathrm{G}, \mathrm{Acc}} \quad$ Accumulated amount of gas products, $\mathrm{mg}$

$W_{\mathrm{G}, \mathrm{Acc}, \mathrm{f}}$ Values of $W_{\mathrm{G}, \mathrm{Acc}}$ at $45 \mathrm{~min}, \mathrm{mg}$

$W_{\mathrm{H} 2 \mathrm{O}} \quad$ Moisture content of sample, wt.\%

$W_{\mathrm{ST}} \quad$ Mass of sample at $T_{\mathrm{ST}}$ or $t_{\mathrm{ST}}, \mathrm{mg}$

$W_{\mathrm{STF}} \quad$ Total amount of mass pyrolyzed after $t_{\mathrm{ST}},=W_{\mathrm{ST}}-W_{\mathrm{f}}, \mathrm{mg}$

$Y_{\mathrm{W}, \mathrm{i}} \quad$ Yield of component $\mathrm{i}$ in the accumulated gas products with respect to the original dry solid sample, wt.\%

$y_{\mathrm{e}} \quad$ Value of experimental data

$y_{\mathrm{p}} \quad$ Predicted value

$\eta_{\mathrm{ST} / \mathrm{SS}} \quad$ Decomposition efficiency for further pyrolysis of $M_{\mathrm{ST}}$ to $M_{\mathrm{SS}}$ as computed using Eq. (4), wt.\%

\section{References}

ASTM D2015, 2000. Standard Test Method for Gross Calorific Value of Coal and Coke by the Adiabatic Bomb Calorimeter, American Society for Testing and Materials, Conshohocken, PA, USA.

ASTM D3174-04, 2006. Standard Test Method for Ash in the Analysis Sample of Coal and Coke from Coal, American Society for Testing and Materials, Conshohocken, PA, USA.
Atutxa, A., Aguado, R., Gayubo, A.G., Olazar, M., Bilbao, J., 2005. Kinetic description of the catalytic pyrolysis of biomass in a conical spouted bed reactor. Energy and Fuels 19, 765-774.

Bakker, R.R., Jenkins, B.M., 2003. Feasibility of collecting naturally leached rice straw for thermal conversion. Biomass and Bioenergy 25, 597-614.

Bhattacharya, S.C., Salam, P.A., Sharma, M., 2000. Emissions from biomass energy use in some selected Asian countries. Energy 25, 169-188.

Bridgwater, A.V., 2003. Renewable fuels and chemicals by thermal processing of biomass. Chem. Eng. J. 91, 87-102.

Caldeira, M.I.K., Benford, G., Criswell, D.R., Green, C., Herzog, H., Jain, A.K., Kheshgi, H.S., Lackner, K.S., Lewis, J.S., Lightfoot, H.D., Manheimer, W., Mankins, J.C., Mauel, M.E., Perkins, L.J., Schlesinger, M.E., Volk, T., Wigley, T.M.L., 2002 Advanced technology paths to global climate stability: energy for a greenhouse planet. Science 298, 981-987.

Chen, G., Andries, J., Luo, Z., Spliethoff, H., 2003a. Biomass pyrolysis/gasification for product gas production: the overall investigation of parametric effects. Energy Convers. Mgmt. 44, 1875-1884.

Chen, G., Andries, J., Spliethoff, H., 2003b. Catalytic pyrolysis of biomass for hydrogen rich fuel gas production. Energy Convers. Mgmt. 44, 2289-2296.

Cheng, H.H., Chen, S.S., Wu, Y.C., Ho, D.L., 2007. Non-thermal plasma technology for degradation of organic compounds in wastewater control: a critical review. J. Environ. Eng. Manage. 17, 427-433.

Demirbas, A., 2005. Relationship between Initial moisture content and the liquid yield from pyrolysis of saw dust. Energy Sources 27, 823-830.

Ferdous, D., Dalai, A.K., Bej, S.K., Thring, R.W., Bakhshi, N.N., 2001. Production of $\mathrm{H}_{2}$ and medium Btu gas via pyrolysis of lignins in a fixed-bed reactor. Fuel Process Technol. 70, 9-26.

Gullu, D., 2003. Effect of catalyst on yield of liquid products from biomass via pyrolysis. Energy Sources 25, 753-765.

Hlina, M., Hrabovsky, M., Kopecky, V., Konrad, M., Kavka, T., Skoblja, S., 2006. Plasma gasification of wood and production of gas with low content of tar. Czechoslovak J. Phys. 56, B1179-B1184.

Huang, H.C., Chang, C.Y., Chen, Y.H., Shie, J.L., Lin, J.P., Wu, C.H., 2004. Resources recovery of waste rayon by pyrolysis: kinetics study. J. Chin. Inst. Chem. Engrs. 35, 623-632.

Huang, Y.F., Kuan, W.H., Lo, S.L., Lin, C.F., 2008. Total recovery of resources and energy from rice straw using microwave-induced pyrolysis. Bioresou. Technol. $99,8252-8258$.

Iranzo, M., Cañizares, J.V., Roca-Perez, L., Sainz-Pardo, I., Mormeneo, S., Boluda, R., 2004. Characteristics of rice straw and sewage sludge as composting materials in Valencia (Spain). Bioresour. Technol. 95, 107-112.

Liang, X.H., Kozinski, J.A., 2000. Numerical modeling of combustion and pyrolysis of cellulosic biomass in thermogravimetric systems. Fuel 79, 1477-1486.

Lin, K.L., Lin, C.Y., 2006. Feasibility of using ash from sludge incineration as raw materials for eco-cement. J. Environ. Eng. Manage. 16, 39-46.

Mckendry, P., 2002. Energy production from biomass (part 1): overview of biomass Bioresour. Technol. 83, 37-46.

Merida, W., Maness, P.C., Brown, R.C., Levin, D.B., 2004. Enhanced hydrogen production from indirectly heated, gasified biomass, and removal of carbon gas emissions using a novel biological gas reformer. Int. J. Hydrogen Energy 29, 283-290.

Pendyal, B., John, M.M., Marshalf, W.E., Ahmednaa, M., Raoa, R.M., 1999. The effect of binders and agricultural by-products on physical and chemical properties of granular activated carbons. Bioresour. Technol. 68, 247-254.

Pütün, A.E., Apaydm, E., Pütün, E., 2004. Rice straw as a bio-oil source via pyrolysis and steam pyrolysis. Energy 29, 2171-2180.

Shie, J.L., Chang, C.Y., Lin, J.P., Lee, D.J., Wu, C.H., 2001. Thermal degradation kinetics of oil sludge in the presence of carbon dioxide. J. Chin. Inst. Environ. Eng. 11, 307-316.

Shie, J.L., Chen, Y.H., Chang, C.Y., Lin, J.P., Lee, D.J., Wu, C.H., 2002a. Thermal pyrolysis of polyvinyl alcohol and its major products. Energy and Fuels 16, 109-118.

Shie, J.L., Chang, C.Y., Lin, J.P., Lee, D.J., Wu, C.H., 2002b. Effect of feeding oxygen fraction on gas emission and solid residue from oxidative thermal treatment of oil sludge. J. Chin. Inst. Environ. Eng. 12, 65-76.

Shie, J.L., Lin, J.P., Chang, C.Y., Lee, D.J., Wu, C.H., 2002c. Use of calcium compounds as additives for oil sludge pyrolysis. J. Chin. Inst. Environ. Eng. 12, 363-371.

Srinivasa Reddy, M., Basha, S., Joshi, H.V., Sravan Kumar, V.G., Jha, B., Ghosh, P.K., 2005. Modeling the energy content of combustible ship-scrapping waste at Alang-Sosiya, India, using multiple regression analysis. Waste Manage. 25, 747754.

Shie, J.L., Chang, C.Y., Tu, W.K., Tang, Y.C., Liao, J.K., Tzeng, C.C., Li, H.Y., Yu, Y.J., Kuo, C.H., Chang, L.C., 2008. Major products obtained from plasma torch pyrolysis of sunflower-oil cake. Energy and Fuels 22, 75-82.

Tang, L., Huang, H., 2005a. Plasma pyrolysis of biomass for production of syngas and carbon adsorbent. Energy and Fuels 19, 1174-1178.

Tang, L., Huang, H., 2005b. Biomass gasification using capacitively coupled RF plasma technology. Fuel 84, 2055-2063.

Tsai, W.T., Chang, C.Y., Wang, S.Y., Chang, C.F., Chien, S.F., Sun, H.F., 2001 Preparation of activated carbons from corn cob catalyzed by potassium salts and subsequent gasification with $\mathrm{CO}_{2}$. Bioresour. Technol. 78, 203-208.

Tu, W.K., Shie, J.L., Chang, C.Y., Chang, C.F., Lin, C.F., Yang, S.Y., Kuo, J.T., Shaw, D.G., Lee, D.J., 2008. Pyrolysis of rice straw using radio-frequency plasma. Energy and Fuels 22, 24-30.

Waldner, M.H., Vogel, F., 2005. Renewable production of methane from woody biomass by catalytic hydrothermal gasification. Ind. Eng. Chem. Res. 44, 45434551. 
Worasuwannarak, N., Sonobe, T., Tanthapanichakoon, W., 2007. Pyrolysis behaviors of rice straw, rice husk, and corncob by TG-MS technique. J. Anal. Appl. Pyrol. 78, 265-271.

Wu, C.H., Chang, C.Y., Tseng, C.H., Lin, J.P., 2003. Pyrolysis product distribution of waste toilet paper in a laboratory-scale TGA reactor. J. Chin. Inst. Environ. Eng. $13,67-76$.
Yaman, S., 2004. Pyrolysis of biomass to produce fuels and chemical feed stocks. Energy Convers. Mgmt. 45, 651-671.

Zhao, Z.L., Huang, H.T., Wu, C.Z., Li, H.B., Chen, Y., 2001. Biomass pyrolysis in an argon/hydrogen plasma reactor. Chem. Eng. Tech. 24, 197-199. 